\title{
Differences in regulation of carbohydrate metabolism during early fruit development between domesticated tomato and two wild relatives
}

\author{
A. J. Kortstee • N. J. G. Appeldoorn • \\ M. E. P. Oortwijn · R. G. F. Visser
}

Received: 5 February 2007 / Accepted: 23 April 2007 / Published online: 22 May 2007

(C) Springer-Verlag 2007

\begin{abstract}
Early development and growth of fruit in the domesticated tomato Solanum lycopersicum cultivar Money Maker and two of its wild relatives, S. peruvianum LA0385 and S. habrochaites LA1777, were studied. Although small differences exist, the processes involved and the sequence of events in fruit development are similar in all three species. The growth of developing fruits is exponential and the relative growth rate accelerates from 5 days after pollination (DAP 5) to DAP 8, followed by a decline during further development. Growth is positively correlated to the standard "Brix plus starch" in the period DAP 8-DAP 20. Carbohydrate composition and levels of sugars and organic acids differ in fruits of the wild accessions compared to domesticated tomato. The wild accessions accumulate sucrose instead of glucose and fructose, and ripe fruits contain higher levels of malate and citrate. The enzymes responsible for the accumulation of glucose and fructose in domesticated tomatoes are soluble invertase and sucrose synthase. The regulation of initial carbohydrate metabolism in the domesticated tomato differs from that in the wild species, as could be concluded from measuring activities of enzymes involved in primary carbohydrate metabolism. Furthermore, changes in the activity of several enzymes, e.g., cell wall invertase, soluble invertase, fructokinase and phosphoglucomutase, could be attributed to
\end{abstract}

Electronic supplementary material The online version of this article (doi:10.1007/s00425-007-0539-6) contains supplementary material, which is available to authorized users.

A. J. Kortstee $(\bowtie) \cdot$ N. J. G. Appeldoorn · M. E. P. Oortwijn · R. G. F. Visser

Laboratory of Plant Breeding, Department of Plant Sciences,

Wageningen University, P.O. Box 386,

6700 AJ Wageningen, The Netherlands

e-mail: anne.kortstee@wur.nl changes in gene expression level. For other enzymes, additional control mechanisms play a role in the developing tomato fruits. Localization by in-situ activity staining of enzymes showed comparable results for fruits of domesticated tomato and the wild accessions. However, in the pericarp of $S$. peruvianum, less activity staining of phosphogluco-isomerase, phosphoglucomutase and UDPglucosepyrophosphorylase was observed.

Keywords Carbohydrate metabolism · Enzyme activity · Gene expression level · Tomato fruit development

\begin{tabular}{ll}
\multicolumn{2}{l}{ Abbreviations } \\
DAP & Days after pollination \\
CWI & Cell-wall bound invertase \\
SI & Soluble invertase \\
Susy & Sucrose synthase \\
HK & Hexokinase \\
FK & Fructokinase \\
AGPase & ADP-glucosepyrophosphorylase \\
UGPase & UDP-glucosepyrophosphorylase \\
PGI & Phosphoglucoisomerase \\
PGM & Phosphoglucomutase \\
RT-PCR & Real-time PCR \\
Glc & Glucose \\
lin & Gene encoding cell-wall bound invertase \\
tiv & Gene encoding soluble invertase \\
sus & Gene encoding sucrose synthase \\
RGR & Relative growth rate
\end{tabular}

\section{Introduction}

In the early stages of plant growth, the developing shoot with initiating leaves and the growing roots represent 
important sinks. After the start of flowering, developing fruits become important sinks for domestic tomato. Fruit development comprises a cell-division phase which occurs in the pericarp, epidermis and locular and placental tissues of the ovary, followed by a cell-enlargement phase in which the cells enlarge circa ten times. In this second phase, the fruit shows its largest growth and increase in size. From 45 to 55 days after pollination (DAP) onwards, ripening of the fruit-which is not accompanied by further growth-occurs (reviewed by Gillaspy et al. 1993).

The growth rate and (final) size of tomato fruits appears to be largely determined by cellular production during ovary formation and the first 2 weeks after pollination (Bunger-Kibler and Bangerth 1983). The mitotic index of the pericarp increases three-fold from anthesis to 10 days after anthesis (DAA), decreases during the following 15 days when cell expansion starts, and remains quite low during ripening (Joubes et al. 1999). Cell division and its regulation appear to be directly affected by the level of available carbohydrates and the form in which they are available (reviewed by Francis and Halford 2006). The regulation of primary carbohydrate metabolism and of the enzymes involved plays an important role in determining carbohydrate composition and level and may, therefore, have a large effect on growth and the strength of sinks (Koch 2004). For instance, in developing cotyledons of Vicia faba beans, prolonged expression of cell-wall-bound invertase (CWI), which brings sucrose into primary metabolism by the enzyme's hydrolytic activity in the apoplast, results in enlarged seeds (Weber et al. 1998). This seed enlargement is caused by an increase in the number of cotyledon cells available for the process of cellular expansion. The presence of CWI is generally considered to be important for establishing and determining sink strength and for apoplastic unloading. In addition, it is thought that the sucrose-hexose converting activity of CWI in the unloading zone, such as in the developing cotyledons, leads to favorable environmental conditions for the maintenance of mitotic activity and may, thereby, enhance growth potential (Roitsch and Gonzalez 2004). Evidence for a role of carbohydrate metabolism in organogenesis is also provided by Pien et al. (2001), who showed spatial regulation of AGPase, Susy and SNF1-like kinase in leaf apical meristems, although the precise mechanism underlying this regulation is not clear.

Recent breeding strategies aimed at increased yield or different metabolite compositionmake use of natural variation by introducing wild traits into domesticated tomato (Eshed and Zamir 1995). An interspecific cross with Solanum habrochaites resulted in a tomato breeding line with increased starch accumulation in the young fruit which was associated with the $S$. habrochaites-derived allele for AGPase (Schaffer et al. 2000). Introgression of a CWI iso- form (lin5) from S. pennellii LA0716 into S. lycopersicum resulted in a higher fruit yield and a higher soluble sugar content. This result reflects the potential of enzyme isoforms from wild species to enhance the growth and sink strength of domestic tomato fruit (Fridman et al. 2004).

Early stages of fruit development are of importance for characteristics of mature fruits including fruit weight and composition of primary metabolites. The genes responsible for the variation in composition could be involved in metabolism, transport or partitioning. We have initiated a comparative study of developmental changes in the initial steps in carbohydrate metabolism during early fruit development in the S. lycopersicum cv Money Maker and the wild accessions $S$. peruvianum LA0385 and S. habrochaites LA1777. Differences between accessions have been described before but concern only the activity of a limited number of enzymes, e.g., invertase and sucrose synthase (Yelle et al. 1988; Miron and Schaffer 1991; Sun et al. 1992; Stommel 1992; Balibrea et al. 2003). We describe not only the enzymes involved in sucrose breakdown but the next steps in carbohydrate metabolism as well. Fructose and glucose the breakdown products of sucrose, can be phosphorylated by the enzymes fructokinase and hexokinase, We also describe the activity and regulation of enzymes involved in the conversion of sucrose to starch which were until now not so well studied in developing fruits of tomato, namely: UDP-glucosepyrophosphorylase, phosphoglucomutase and phosphoglucoisomerase. our focus is on the very first stages in fruit development, from DAP 0 to DAP 20, but for comparison, growth and development were studied until fruits were ripe. Enzyme activity was measured in whole fruit extracts. Insitu activity staining showed the spatial regulation of these enzymes and quantitative real-time PCR was used to determine temporal regulation of gene expression and distinguish between individual members of gene families.

\section{Materials and methods}

Plant material and growth conditions

Nomenclature of the tomato varieties used in this study was adopted from Knapp et al. (2004). Seeds of the S. lycopersicum cv Money Maker and seeds from the S. habrochaites accession LA1777 and the S. peruvianum accession LA0385 were obtained from the Centre for Genetic Resources (CGN, Wageningen, The Netherlands). Seeds were sown in soil mixed with river sand (50:50, w/w) and placed in a climate cell. The conditions applied were a $12 \mathrm{~h}$ day-night regime with temperatures of $22^{\circ} \mathrm{C}$ during the day and $16^{\circ} \mathrm{C}$ during the night and an irradiance of $140 \mu \mathrm{mol}$ photons $\mathrm{m}^{2} \mathrm{~s}^{-1}$. The relative humidity varied between 65 
and $90 \%$ with an average of $80 \%$. After 2 weeks the young plants were transferred to 121 pots filled with soil to which $2 \mathrm{~g}$ of osmocote per liter (slow-release fertilizer) were added. The S. lycopersicum and S. peruvianum LA0385 plants were allowed to develop into mature flowering plants under the same conditions. Because of differences in optimal growth conditions plants of $S$. habrochaites were placed in a second climate cell with similar conditions except for a relative humidity between 55 and $60 \%$ and the addition of extra light up to $420 \mu \mathrm{mol}$ photons $\mathrm{m}^{-2} \mathrm{~s}^{-1}$ as required for induction of flowering of this accession. During the whole period of growth and fruit formation, the plants received extra liquid fertilizer every 2 weeks.

Fresh- and dry-weight measurements of early developing fruits

Fruit formation was initiated on 10-22 plants per species by pollinating tagged flowers. Open flowers of $S$. peruvianum LA0385 and $S$. habrochaites LA1777 were sib pollinated. Fruits were harvested 5, 8, 10, 11, 13, 20, 27, 37, 47 and 57 days after pollination (DAP) and when fruits were ripe. DAP 5 is the earliest possible time to discriminate between fertilized and non-fertilized egg cells. Harvesting was done around midday by a swift separation of the developing fruits from the flower base, followed by immediate freezing in liquid $\mathrm{N}_{2}$ and storage at $-80^{\circ} \mathrm{C}$ for later use. For biochemical analyses, generally 24-28 fruits of the two wild species and 14-28 fruits of $S$. lycopersicum were pooled. The numbers of unpollinated ovaries harvested for biochemical analyses was higher than 90 and could amount to as many as 200 per harvest. At DAP 5 the numbers for the two wild species, but not for $S$. lycopersicum, were also generally higher than between DAP 8-20 (up to 97). Simultaneously an equal or representative number (with a maximum of around 30) of similar-sized fruits was collected from the same (opposite position on the) trusses and weighed in closed tubes as soon as possible. In order to obtain information on the variation in fruit size, the fruits of stage DAP 5 and onwards were also individually weighed. These fruits were pooled again, stored at $-20^{\circ} \mathrm{C}$ and used for determination of dry weight (DW). For this purpose and for the biochemical analyses, the collected fruit samples stored per harvest at -80 and $-20^{\circ} \mathrm{C}$ were freeze-dried under very-low-pressure conditions ('vacuum') at $-20^{\circ} \mathrm{C}$. In order to get complete dehydration of fruits from stage DAP 8 and older, the frozen fruits were cracked open and split into several parts without any loss of frozen material. After freeze-drying, the pooled fruits used for fresh-weight (FW) determination were again weighed for the determination of dry matter percentages, and the pooled fruits harvested for the biochemical analyses were grounded into fine powder and extracted as described below. Sink strength was expressed as the dry matter accumulation rate which was calculated for each period according to the equation $\left(\mathrm{DW}_{t 2}-\mathrm{DW}_{t 1}\right) /(t 2-t 1)$. The " $t$ " stands for the number of days after pollination. Sink activity was expressed as the increase in dry weight per unit of dry weight present per unit of time using the equation $\left(\mathrm{DW}_{t 2}-\mathrm{DW}_{\mathrm{t} 1}\right) /(t 2-t 1)$ as described by Wang et al. (1993).

Extraction and determination of starch content, neutral sugars and organic acids

The starch content was measured as described by the manufacturer using a kit (No. 0207748; Boehringer, Mannheim, Germany). Five milligram of ground, freeze-dried fruit tissue was extracted thrice for $5 \mathrm{~min}$ with $150-200 \mu \mathrm{l}$ of $80 \%$ $(\mathrm{v} / \mathrm{v})$ ethanol at a temperature of $80^{\circ} \mathrm{C}$. After each extraction, the insoluble material was pelleted by centrifugation (5 min, 15,000 g) and the supernatants pooled. Two hundred microliters of the pooled supernatant was evaporated in a vacuum centrifuge and the remaining pellet was dissolved in $200 \mu \mathrm{l}$ of Milli-Q. Aliquots were used for the measurement of sucrose, hexose, citrate and malate contents according to the manufacturer's instructions for the corresponding assay kits (No. 0716260; Boehringer Mannheim).

Extraction and activity determination of enzymes

Total extracts for assays of enzymes were prepared by homogenizing 7-8 $\mathrm{mg}$ of the powdered, freeze-dried fruit tissue basically as described previously (Appeldoorn et al. 1997, 1999). The activities of different enzymes were determined in $300 \mu \mathrm{l}$ of assay medium at $20^{\circ} \mathrm{C}$. The reactions were started by adding extract or substrate and measured spectrophotometrically. Blanks had the same reaction mixture but without substrate.

Enzyme activities were assayed as described by Appeldoorn et al. $(1997,1999)$.

In-situ staining of enzyme activity

Enzyme activity was visualized as described by Sergeeva and Vreugdenhil (2000) by coupling the reduction of NAD to the reduction of NBT, resulting in the precipitation of blue tetrazolium salt at the location of enzyme activity.

Quantitative Real time-time PCR analysis of gene expression

PCR primers were designed with the Primer Express program Version 1.0 from P\&E Biosystems to produce a short amplicon (100-200 bp). The sequences used to design primers and the primer sequences can be found in Supplementary Table 1 . 
Table 1 Organic acid content as percentage of dry weight of fruits from S. lycopersicum (MM), S. peruvianum (P) and S. habrochaites $(\mathrm{H})$ during fruit development, at different Days After Pollination (DAP)

\begin{tabular}{llllllrr}
\hline & & DAP 0 & DAP 5 & DAP 8 & DAP 13 & DAP 20 & Ripe \\
\hline Citrate & MM & $2.27 \pm 0.14$ & $2.16 \pm 0.26$ & $1.55 \pm 0.06$ & $2.18 \pm 0.01$ & $2.39 \pm 0.11$ & $3.29 \pm 0.21$ \\
& P & $1.21 \pm 003$ & $2.01 \pm 0.01$ & $2.44 \pm 0.01$ & $2.69 \pm 0.02$ & $3.7 \pm 0.48$ & $6.39 \pm 0.01$ \\
& H & $1.68 \pm 0.02$ & $2.17 \pm 0.01$ & $2.11 \pm 0.05$ & $2.25 \pm 0.02$ & $2.13 \pm 0.09$ & $7.76 \pm 0.12$ \\
Malate & MM & $0.94 \pm 0.02$ & $1.36 \pm 0.03$ & $2.08 \pm 0.01$ & $2.43 \pm 0.17$ & $3.75 \pm 0.28$ & $1.63 \pm 0.08$ \\
& P & $1.03 \pm 0.01$ & $1.58 \pm 0.01$ & $2.62 \pm 0.01$ & $3.13 \pm 0.01$ & $3.06 \pm 0.02$ & $1.90 \pm 0.01$ \\
& H & $0.53 \pm 0.01$ & $1.1 \pm 0.01$ & $2.04 \pm 0.01$ & $4.14 \pm 0.01$ & $3.88 \pm 0.01$ & $0.86 \pm 0.03$ \\
\hline
\end{tabular}

Values are the mean of two replications \pm SD

By using the RNeasy ${ }^{\circledR}$ plant mini kit (Qiagen), RNA was prepared from 5-30 frozen fruits ground in liquid nitrogen. cDNA was prepared with the SuperScript ${ }^{\mathrm{TM}}$ III First-strand Synthesis System for Real Time-time PCR (Invitrogen, 18080-051). SYBR ${ }^{\circledR}$ Green PCR Master Mix (Applied Biosystems) was used on a BIORAD MyiQ ${ }^{\mathrm{TM}}$ Single Color Real Time-Time PCR detection system. The program of the thermocycler was set at: denaturation for $10 \mathrm{~min}$ at $95^{\circ} \mathrm{C}$ followed by 40 cycles of $15 \mathrm{~s}$ at $95^{\circ} \mathrm{C}$ and $1 \mathrm{~min}$ annealing and extension at $60^{\circ} \mathrm{C}$. Sixty-one cycles of $60^{\circ} \mathrm{C}+0.5^{\circ} \mathrm{C}$ were used for the melting curves. Relative quantification of the target RNA expression level and standard deviation was performed using the comparative $\mathrm{Ct}$ method according to the User Bulletin \# 2 (ABI PRISM, Applied Biosystems) 7700 Sequence Detection System (Applied Biosystems). GeneMath XT (Applied Math) software was used to prepare Fig. 5.

\section{Results}

Growth and development

Fruits harvested at different time points are shown as an inset in Fig. 1a. Note the differences in size, color and overall appearance between fruits of $S$. lycopersicum and S. peruvianum. Growth was measured as an increase in the fresh weight (FW) of individual fruits (Fig. 1a). Fruits of the domesticated tomato $S$. lycopersicum showed a tenfold higher FW compared to fruits of the wild relatives; the FW of $S$. lycopersicum is shown with an additional $y$-axis (Fig. 1a). From DAP 8 onwards, growth of the fruits was exponential. The dry matter content declined from almost $20 \%$ at the time of pollination to around $10 \%$ at DAP 13 (Fig. 1b). During further growth and development of the fruits, the dry matter content increased slightly for $S$. habrochaites and S. peruvianum but remained at $10 \%$ for $S$. lycopersicum. Sink strength is depicted in Fig. 1c as the increase in dry weight per day. For S. lycopersicum a second $y$-axis was added in the graph. From DAP 3 to DAP 8, sink strength increased slowly in the fruits of all three tomato species. From DAP 13 onwards, a sharp increase in sink strength could be observed, and from DAP 27 until ripening, this process continued at a slower pace. In Fig. 1d, the sink activity is presented as the relative growth rate (RGR). From DAP 3 to DAP 8, an acceleration of growth was observed for the fruits of all three tomato species, with the highest growth rate at DAP 8. After DAP 8, the RGR decreased sharply; in fruits of $S$. habrochaites, the RGR reached its lowest level at DAP 20 and remained unchanged until the fruits were ripe. For fruits of $S$. lycopersicum and $S$. peruvianum, RGRs decreased at a slower pace but reached similar levels at the stage of ripening.

Carbohydrate levels

The levels of glucose, fructose, sucrose, starch, citrate and malate were measured during growth and development and are presented in Fig. 2 and Table 1. Glucose (Fig. 2a) and fructose (Fig. 2b) levels increased in fruits of $S$. lycopersicum during the whole period of fruit setting and ripening. In fruits of $S$. habrochaites and $S$. peruvianum, glucose and fructose levels increased from DAP 5 to DAP 20 but decreased towards ripening. Sucrose levels in fruits of S. lycopersicum temporaryly increased during development (Fig. 2c). In fruits of S. peruvianum and S. habrochaites, sucrose levels rose sharply toward ripening. Starch levels in the fruits of all three tomato species increased in the period DAP 0-DAP 20 but declined thereafter (Fig. 2d).

Levels of citrate and malate are shown in Table 1. In the developing fruits of all three species, malate content increased during development, although $S$. habrochaites and $S$. peruvianum fruits accumulated significantly more citrate than S. lycopersicum. Malate contents of developing fruits increased in the period DAP 0-DAP 20 in S. lycopersicum, as well as in the wild accessions. In the ripe fruits of all three accessions, malate content was again lower.

The standard Brix is defined as indicative of the total content of soluble solids (sugars, organic acids and other soluble compounds) in fruits. As sugars and organic 

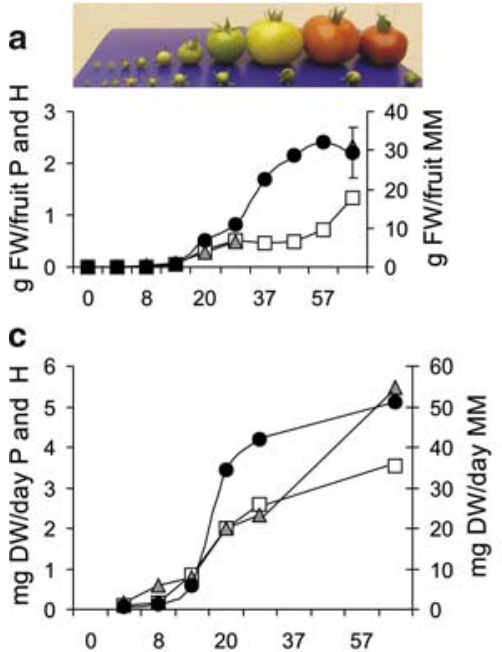

Days After Pollination

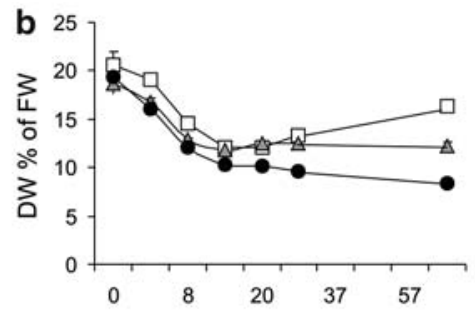

d

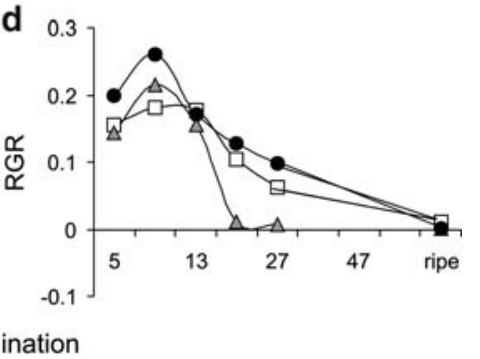

Fig. 1 Growth characteristics of fruits harvested at different time points during development of the Solanum lycopersicum cv Money Maker (MM, black circles), Solanum habrochaites LA 1777 (H, gray triangles) and Solanum peruvianum LA0385 ( $P$, open squares). a Fresh weight per fruit, note the secondary $y$-axis for $S$. lycopersicum $(M M)$. The inset shows a picture of fruits harvested at different time points. Upper row of fruits is from the S. lycopersicum cv Money

acids do form the main components of Brix, we apply the term 'Brix' for the total sum of sucrose, hexose and organic acid (citrate and malate) contents. In combination with the starch content, a new standard composed of Brix plus starch can be proposed. This standard represents the sum of products of sink-storage-related activities and might as such reflect developmental changes in the capacity for combined sink-storage-related activities and may, thereby, partially reflect sink strength per fruit weight. In ovaries at DAP 0, the level of this new proposed standard was comparable in the three tomato species (Fig. 2e). During the very early stages of fruit formation (DAP 0-DAP 8), this standard remained at a constant level in the fruits of all three species. After this stage, the level started to increase in a highly similar manner in S. lycopersicum and S. peruvianum fruits, and a similar, although delayed, increase could also be observed for $S$. habrochaites fruits.

Enzyme activities related to primary carbohydrate metabolism

The activities of several enzymes involved in primary carbohydrate metabolism were measured during the period DAP 0-DAP 20. The activity patterns of the sucrolytic enzyme CWI were very similar between the cultivated $S$. lycopersicum and the two wild species during the whole monitored period (Fig. 3a). The onset of fruit formation
Maker; below are $S$. peruvianum fruits from plants grown in a climate chamber. b Dry matter content as a percentage of the fresh weight. c Sink strength expressed as the dry matter accumulation rate in $\mathrm{mg}$ of DW per day, note the secondary $y$-axis for S. lycopersicum $(M M)$ fruits. d Sink activity evaluated as Relative Growth Ratio. Data represent the mean of two different harvests of at least 25 fruits $\pm \mathrm{SD}$

induced a complete decline in overall CWI activity in all three species. After DAP 10 this enzyme was hardly detectable anymore.

The pattern of vacuolar SI activity during fruit development in S. lycopersicum differed profoundly from that in fruits of S. habrochaites and S. peruvianum (Fig. 3b). Like CWI, the overall activity of the vacuolar SI was high in the ovaries of open flowers. However, after the onset of fruit formation, the activity of SI declined significantly in the very young fruits of the wild species, whereas in the developing fruits of $S$. lycopersicum SI activity remained high. After DAP 3 the activity of SI continued to decline till DAP 20 in the wild species, but to a lesser degree. However, the SI activity in S. lycopersicum fruits remained high during the entire test period.

The second type of sucrolytic enzyme activity tested was Susy, which exhibited, like CWI, a large agreement in its developmental patterns of overall activity in the fruits of the domesticated and wild-type plants (Fig. 3c). At DAP 0, Susy activity was present at substantial levels in the ovaries of all three species. During the first 3 days of fruit formation, a comparable decline in Susy activity of 30-40\% occurred in the fruits of all three species. However, after DAP 5, the Susy activity started to rise again and reached its maximum at about DAP 12 in S. lycopersicum and $S$. peruvianum. In S. habrochaites fruits, the restoration of Susy activity was only marginal. After DAP 13 the overall activity of Susy tended to remain at about the same levels. 

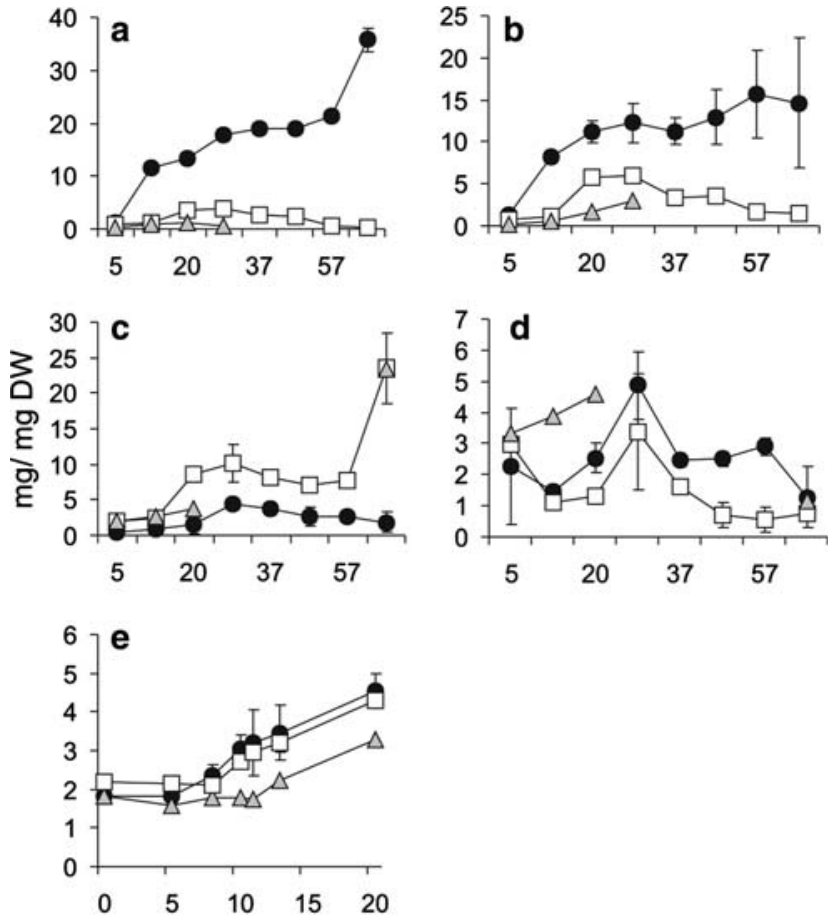

Days After Pollination

Fig. 2 The contents of neutral sugars, organic acids and starch in mg per mg DW ( $y$-axis) plotted against DAP ( $x$-axis) in developing fruits of S. lycopersicum MM (circles), S. habrochaites (triangles) and S. peruvianum (squares) during development. a Glucose, b fructose, $\mathbf{c}$ sucrose, d starch. e The standard "Brix plus starch". Data represent the mean of three independent measurements \pm SD of at least seven fruits

For all three species, the increase in Susy activity in the period from DAP 3 to DAP 20 was at least twofold.

The second group of enzymes whose activities were studied during early fruit development represents the hexose-phosphorylating enzymes, which are capable of directing products of sucrolytic activity further into carbohydrate metabolism. The first one reported is fructokinase, an enzyme known to be highly specific for phosphorylating fructose. In the ovaries at DAP 0, an almost identical level of activity was found for all three species, followed during and after fruit set by a nearly twofold increase by DAP 10 (Fig. 3d). Between DAP 10 and DAP 20, the activity of fructokinase continued to increase slightly in S. habrochaites fruits, but in the fruits of the other two tomato species a small decline in overall fructokinase activities could be observed.

Hexokinase showed a rather constant activity during the different stages of fruit development in all three tomato species (Fig. 3e). In developing fruits of S. lycopersicum, the level stayed nearly constant from the onset of fruit formation. In S. habrochaites fruits, hexokinase activity remained at the same level during the first 10 days of fruit development as in the ovaries of open flowers. After DAP 10, the
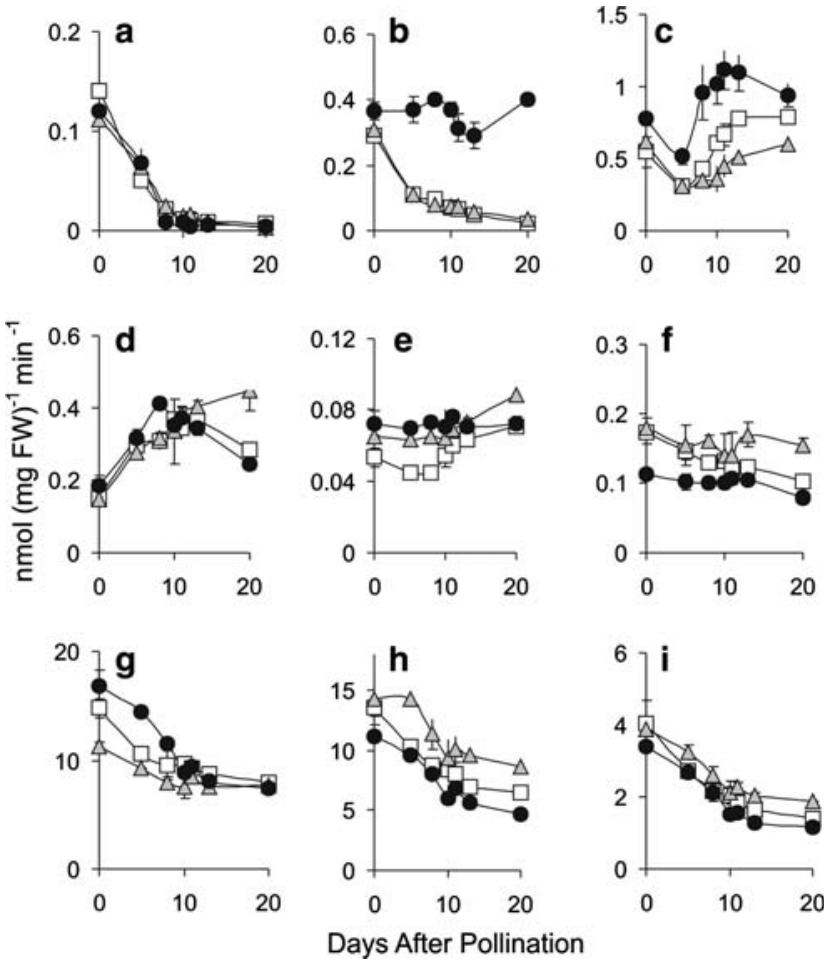

Fig. 3 Activities of enzymes involved in primary carbohydrate metabolism in developing fruits of $S$. lycopersicum MM (circles), S. habrochaites (triangles) and S. peruvianum (squares). On the $x$-axis is time in DAP. Enzyme activity is plotted as nmol substrate per mg FW per minute. Data represent the mean of three independent measurements of at least seven fruits \pm SD. a Cell wall invertase, b soluble invertase, $\mathbf{c}$ sucrose synthase, $\mathbf{d}$ fructokinase, $\mathbf{e}$ hexokinase, $\mathbf{f}$ ADP-glucosepyrophosphorylase, g UDP-glucosepyrophosphorylase, $\mathbf{h}$ phosphoglucomutase, i phosphoglucoisomerase

activity of hexokinase tended to increase slightly till DAP 20 . The activity of hexokinase in $S$. peruvianum seemed to drop a little bit during the first 8 days of fruit formation, but increased until reaching a level similar to that in the developing fruits of $S$. lycopersicum.

The third group of enzymes examined represents those involved in the reversible conversion of UDP-glucose and ADP-Glucose and hexose-phosphates. These enzymes seemed to be subject to rather similar regulation during the different phases of early fruit organogenesis. AGPase, UGPase, PGM and PGI all showed a decline in activity from DAP 0 to DAP 20 (Fig. 3f-i). AGPase catalyses the conversion of glucose-1-phosphate and ATP into ADP-Glucose and pyrophosphate and is considered to be the main rate-limiting enzyme activity in starch synthesis. In developing S. lycopersicum fruit, AGPase activity was constant during the first 10 days after pollination, as is shown in Fig. 3f. In this very early stage, AGPase was declining in the wild tomato fruits, although in a modest way. After DAP 10, AGPase activity in the developing fruits of all three species continued to decline marginally or remained at the same level. 
UDP-glucose pyrophosphorylase (UGPase) catalyses the conversion of one of the two products of the Susy-mediated sucrose-breakdown reaction, i.e., UDP-glucose, with pyrophosphate into glucose-1-phosphate and UDP. The pattern of UGPase activity during early fruit development was highly comparable for all three tomato species (Fig. 3g). A modest decline from the onset of fruit formation at DAP 0 occurred till the activity reached rather equal levels at DAP 10, followed by a further slow decline till DAP 20.

For the overall activities of phosphoglucomutase (PGM), which catalyses the reversible conversion of glucose-1-phosphate into glucose-6-phosphate, similar developmental patterns were observed during the different phases of fruit development in all three species (Fig. 3h). A decline of about $40 \%$ during the first 10 days was measured, followed by a further slight decline.

The pattern of activity of phosphogluco-isomerase (PGI), which catalyses the reversible conversion of glucose-6-phosphate into fructose-6-phosphate, highly resembled the pattern observed for UGPase during early fruit development. A twofold decline in activity from DAP 0 to DAP 10 occurred and was followed by a slight decline or maintenance at a constant level till DAP 20 of the developing fruits in all three species (Fig. 3i).

In-situ staining of enzyme activity

The spatial distribution of the enzymes measured in Fig. 3 was visualized by in situ staining for activity in fruits of $S$. lycopersicum and S. peruvianum. Due to a lack of material, fruits of $S$. habrochaites were not studied. Activity of the enzyme is coupled to the formation of a blue precipitate. Fruits were stained for activity at different developmental stages, e.g., DAP 5, DAP 8 and DAP 13, in order to detect temporal regulation.

Most of the enzymes showed activity in all fruit tissues with little difference in staining intensity except for the tissue surrounding the seeds, which was often stained more intensely. The activity of Susy in fruits of S. lycopersicum and $S$. peruvianum at DAP 13 is shown as an example (Fig. 4a). The tissue surrounding the seeds is stained more than the rest of the fruit, which shows an equal degree of staining.

In the pericarp of $S$. peruvianum, less staining activity of PGM, PGI and UGPase/AGPase was observed compared to the rest of the fruit tissues. The fruits of S. lycopersicum were evenly stained (Fig. 4b). The differences in S. peruvianum were observed in the fruits at DAP 5 and DAP 8; in fruits at DAP 13 the differences were less pronounced. Figure $4 \mathrm{~b}$ shows the results for fruits at DAP 8 stained for the activity of PGI. Starch was stained by iodine and was present in pericarp and in the placental tissue of the fruits (Fig. 4c).

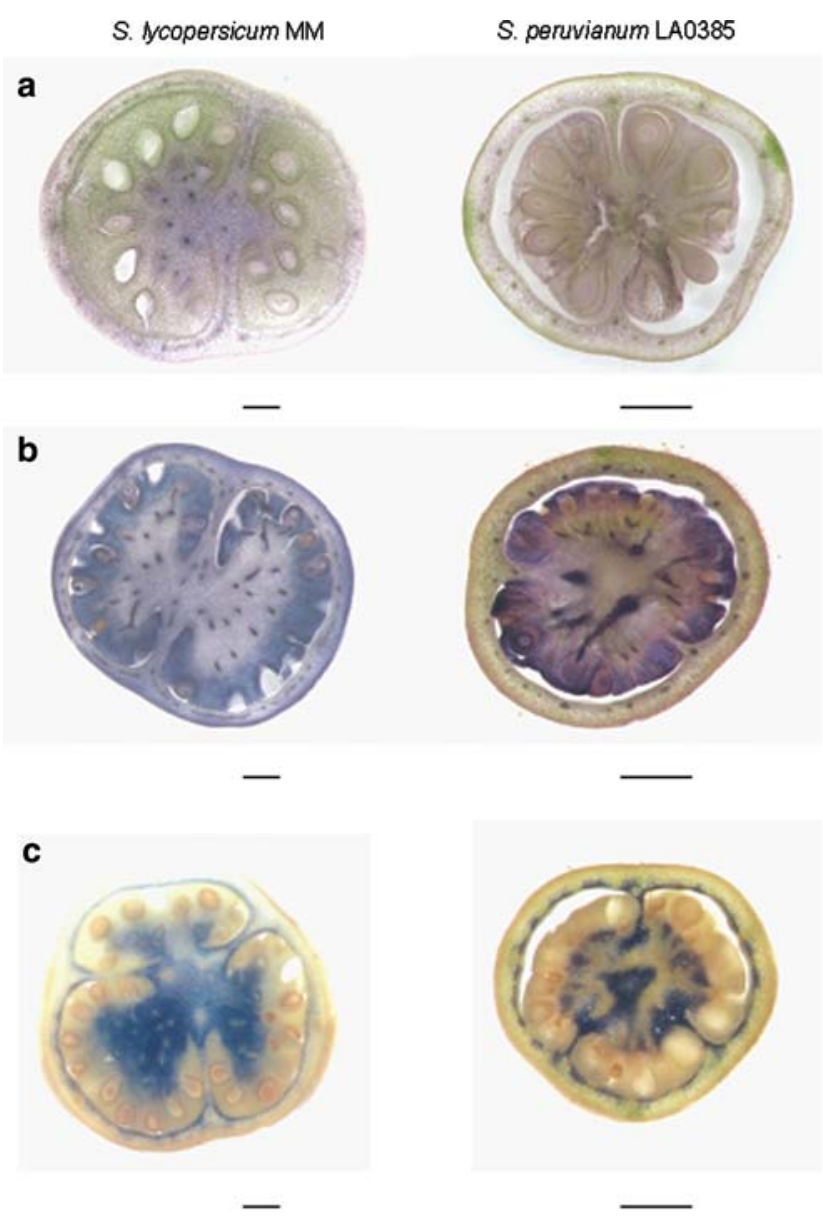

Fig. 4 In situ staining of enzyme activity. a Sucrose synthase in fruits of $S$. lycopersicum MM and S. peruvianum at 13 DAP. b Phosphoglucoisomerase in fruits eight DAP. c Iodine staining of starch in fruits eight DAP of $S$. lycopersicum $\mathrm{MM}$ and $S$. peruvianum. Bar $=1 \mathrm{~mm}$

For HK and FK activities, no clear-cut results were obtained in tissues of S. peruvianum. In fruits of S. lycopersicum, hexokinase and fructokinase activities were equally distributed in all tissues, with a bit more staining in the tissue surrounding the seeds. Invertase activity was found in all tissues in both species.

\section{Real time-PCR analysis of gene expression}

To determine if the differences in enzyme activity between the different tomato accessions were controlled at the transcriptional level, we measured the expression levels of several genes. The expression of the invertase genes $t i v-1, \operatorname{lin} 5$, lin6, lin7, lin8; the sucrose synthase genes Sus2 and Sus3; genes encoding the subunits of ADP-glucosepyrophosphorylase Apl1, ApL2, ApL3 and ApS 1; the fructokinase-encoding genes $f k 1$ and $f k 2$; the hexokinase-encoding genes $h k 1$, $h k 2$ and $h k 4$; and the cytosolic forms of pgi and pgm were studied by means of quantitative real-time PCR. 
The expression level of each gene was normalized to the expression of actin in the same cDNA sample, and the results are shown in Fig. 5 in false colors. Tiv-1 expression in fruits of $S$. lycopersicum increased during development, but in fruits of the wild accessions this gene was expressed at a very low level. Expression of lin6, 7 and 8 could not be detected in developing fruits. Expression of lin 5 in fruits of domesticated tomato decreased beginning at fertilization, but increased towards ripening, whereas in fruits of the wild accessions the expression of this gene stayed low during the whole period of fruit development and ripening. Expression of sus 2 was higher in fruits of domesticated tomato compared to the wild accessions, and during fruit development an increase was followed by a decrease. The other sucrose synthase gene, sus3, was expressed at higher levels in fruits of $S$. peruvianum compared to $S$. lycopersicum, and sus3's expression increased later during development. The most prominently expressed fructokinase gene is $f k 2$, which showed an overall decline in expression levels during development. Expression of $f k l$ was absent in fruits of $S$. habrochaites. Of the hexokinase genes expressed during fruit growth and development, $h k 1$ and $h k 2$ showed a decrease in expression levels during fruit development in all three accessions, whereas $h k 4$ showed a temporary increase in expression level. No significant differences were found between the accessions. The major expressed isoform of AGPase, ApL1, was differentially expressed between the three accessions, with an increase followed by a decrease; $A p L 2$ showed the opposite pattern: a decrease followed by a slow increase in expression level. ApS1 showed similar expression levels as $A p L 1$, with a peak around 27 DAP. ApL3 could not be detected at all. The cytosolic isoform of $p g i$ showed an increase in expression level in fruits of domesticated tomato towards ripening but stayed low in fruits of the wild accessions. Expression levels of pgm increased during fruit growth and development for $S$. lycopersicum, but in fruits of $S$. peruvianum, the expression level of $p g m$ was only temporarily increased, and in fruits of $S$. habrochaites, pgm levels in ripe fruits were similar to those in growing fruits.

\section{Discussion}

Fruit growth is similar in domesticated and wild tomato accessions

Based on our own data we conclude that the processes of fruit development and growth in S. lycopersicum, S. habrochaites and S. peruvianum are similar The characteristics of this growth and development are : an exponential increase in FW from DAP 8 onwards as shown in Fig. 1a (reflected by a similar increase in DW, data not shown); a decrease in
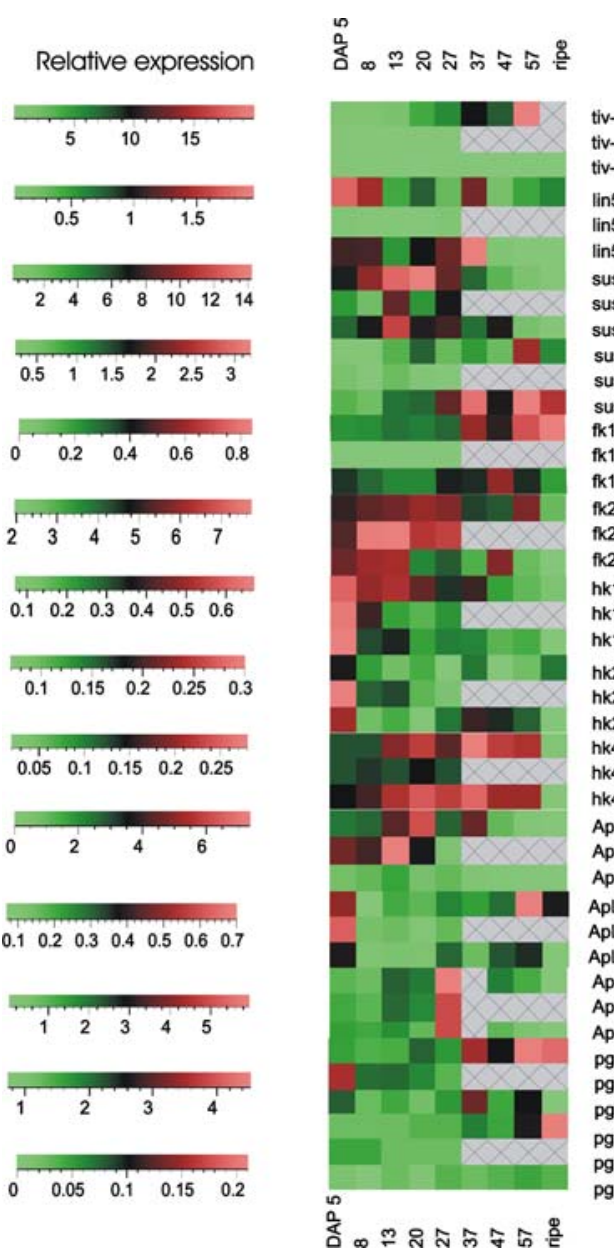

Fig. 5 Relative transcript levels as false-color boxes during the development of fruits from S. lycopersicum, S. peruvianum and S. habrochaites. For each gene, a separate scale is presented on the left. Values for expression levels are normalized to actin

percent of DW (Fig. 1b); an increase in sink strength (Fig. 1c); and an acceleration of RGR from DAP 5 to DAP 8, with RGR peaking at DAP 8 (Fig. 1d).

At DAP 0 the average fresh weight of the ovaries of domestic tomato was about three times higher than that of the wild species. This probably reflects a large difference in ovarian cell number and may thereby explain the large difference in absolute fruit growth between domestic tomato and the wild species right after the initiation of the cell division phase. A major Quantitative Trait Locus for fruit size is encoded by the $f w 2.2$ gene (Frary et al. 2000). The difference between the domesticated and the wild alleles is in the regulation of expression rather than in changes in the fw2.2. protein (Cong et al. 2002). Fw2.2 is associated with a modulation of the size of pre-anthesis ovaries. $F w 2.2$ alleles of $S$. habrochaites and S. peruvianum probably resemble the pennelli allele. Since fruit size partly depends on cell number at anthesis (Bunger-Kibler and Bangerth 1983), fruits from the wild species are smaller. 
After the period in which growth is caused by cell proliferation only, a phase occurs in which growth of the tomato fruits is caused by both cell proliferation and cell enlargement, followed by a phase in which growth is caused predominantly by cell enlargement. Enlarging cells need osmotic pressure in order to grow (Cosgrove 1997). The main osmotica in tomato fruits are organic acids (stored in the vacuole as potassium salts) and sugars (Ho and Hewitt 1986).

In our results we see exponential growth from DAP 8 onwards and an increase in glucose and fructose content. The lower levels of hexoses in fruits of the wild tomato species probably result in a less dramatic increase in growth. The increased levels of citrate and malate are probably not able to compensate for this.

\section{Carbohydrate contents}

One of the major contributors to Brix plus starch is the organic acid content, in which citrate and malate are the predominant components. Near the time of ripening, the citrate content of fruits of the wild species was much higher than in the domesticated species. During fruit development and ripening, the citrate content of fruits of S. lycopersicum was nearly constant. The malate content exhibited a temporal increase in fruits of S. lycopersicum, as well as in fruits of $S$. peruvianum and $S$. habrochaites. In fruits of the wild accession $S$. habrochaites, the malate accumulation showed the most pronounced change The results presented in this paper support the conclusion that fruits of wild tomato plants contain significantly more citrate and malate than those of domesticated plants (Schauer et al. 2005), although S. pimpinellifolium is an exception.

From our results we could detect a positive correlation between growth and brix and starch in wild and domesticated species. Dinar and Stevens (1981) described the relationship between total soluble solid content in the ripe fruit and starch content in the young developing fruit. We show that such a correlation is already visible in the early stages of development (Fig. 2e) and holds for S. lycopersicum as well as for $S$. habrochaites and $S$. peruvianum in the period DAP 0-20.

Susy and SI are responsible for low sucrose and high hexose levels in domesticated tomato

The most striking difference in carbohydrate composition between domesticated tomato and the wild relatives is that ripe $S$. lycopersicum fruits contain significant amounts of glucose and fructose but almost no sucrose, whereas wildtype ripe fruits contain no or low amounts of glucose and fructose and appreciable amounts of sucrose. Since (1) ripening fruits of the domesticated tomato contain higher SI and Susy activities than fruits of the wild types and (2) both enzymes, Susy and SI, are distributed throughout the entire fruit body, we conclude that both enzymes are at least partly responsible for the differences in carbohydrate composition of the domesticated tomato fruits and the fruits of the wild types. The present results are in line with previous work on fruits of a wide variety of tomatoes (Yelle et al.1988; Miron and Schaffer 1991; Stommel 1992; Sun et al. 1992).

Other enzymes and spatial distribution of enzyme activity

The total activities of other enzymes involved in carbohydrate metabolism are more or less similar during the first 20 days of development in domesticated and wild tomato species. In situ staining of enzyme activity showed that in the pericarp of $S$. peruvianum, less activity of PGI, PGM and UGPase/AGPase was found compared to the other tissues in the same developing fruit, whereas in S. lycopersicum fruits, staining in the pericarp was similar to the rest of the fruit. At the moment the physiological significance of the absence of these four enzymes is not clear. These enzymes are all active in the pathway converting sucrose to starch. However, staining for starch did not show less starch accumulation in the pericarp of $S$. peruvianum fruits (Fig. 4c). The role of the pericarp was studied by Obiadalla-Ali et al. (2004) in the tomato cultivar Micro-Tom. In the pericarp of MicroTom, the activity of enzymes involved in sucrose-to-starch conversion was higher compared to the rest of the fruit and sucrose levels were lower in the pericarp compared to placental tissues. However, the fruits used in the present study were less advanced in development.

When comparing our results with those from Shaffer and Petreikov (1997), who measured enzyme activities in different tissues of fruits at DAP 14, we notice some differences: Shaffer and Petreikov found that the activity of Susy was less in the jelly + seed cavity tissue, whereas we observed equal activity staining throughout the fruit. The previously measured UGPase activity was at least fivefold lower in the jelly + seed cavity, in contrast to our in situ staining, where UGPase was found especially associated with vascular tissues and the tissue surrounding the seeds. Fructokinase activity had been found to be lower in the jelly + cavity tissue, and by activity staining we concluded that this activity was equally distributed across the whole fruit. We also concluded that PGM activity was equally distributed over the fruit, and Schaffer and Petreikov (1997) measured less activity in the jelly and seed cavity. Results described for PGM, AGPase and invertase indicated equal activities in all tissues, which we could confirm by activity staining. 


\section{Regulation of gene expression}

Both the expression of the tiv-1 gene and the enzyme activity of SI in fruits of the wild tomato accessions were low compared to $S$. lycopersicum in accordance to what was described (Klann et al. 1993, Miron et al. 2002). We observed lin5 expression in developing fruits of domesticated tomato and also in wild tomato fruits, in contrast to Miron et al. (2002), who found lin5 expression only in the fruits of young (DAP 30) S. lycopersicum. Expression of lin6, lin 7 and lin 8 was too low to be detected by Real Time PCR in developing tomato fruits, as was observed by Northern-blot analysis of the lin gene family (Godt and Roitsch 1997). The CWI enzyme activity decreased during development similarly to lin5 gene expression. CWI and SI activities seem to be regulated by expression levels.

Sucrose synthase enzyme activity in fruits is the sum of the activity of two isoforms but does not seem to reflect the changes in gene expression. Expression of Sus 2 peaked around DAP 20, but expression of Sus3 increased during later development, around DAP 57 (Fig. 5). Expression of Sus3 in developing fruits of S. peruvianum was almost twofold higher compared to $S$. lycopersicum, which is the opposite of the differences in enzyme activity between the two species. Sus3 gene expression in S. habrochaites showed decreased expression during development, as opposed to enzyme activity which was constant or slightly increased. The major form of sucrose synthase mRNA in young tomato fruits comes from the sus2 gene and increased dramatically from DAP 5 to DAP 20 in fruits of S. lycopersicum and similarly in S. peruvianum. In contrast to our findings, Wang et al. (1994) reported that sucrose synthase mRNA reached peak levels in fruits 5-7 days after anthesis. In that case, though, no distinction was made between sus 3 and sus 2 mRNA, but at that stage in development, sus 2 is more highly expressed than sus3. According to Chengappa et al. (1998), sus3 is expressed in the pericarp of ripe fruits and sus 2 most strongly in the placenta of developing fruits. We were able to show expression of sus 3 in the immature developing tomato fruits, although we did not distinguish between different tissues.

Fructokinase expression mirrored enzyme activity in the sense that during early fruit development, levels were nearly constant. The predominantly expressed isoform in tomato fruits of all three accessions was $f k 2$, as was described before by German et al. (2002) for S. lycopersicum. Notably, S. habrochaites lacked $f k 1$ expression (the minor form of fructokinase in the fruits) but had a higher $f k 2$ expression level during early development.

Expression of $h k l$ declined during fruit development, as did the expression level of $h k 2$ in a similar manner in the three accessions. Expression levels of the plastid isoform $h k 4$ in fruits of S. lycopersicum and S. peruvianum showed an increase until DAP 37, followed by a decrease. In fruits of $S$. habrochaites, $h k 4$ was expressed at a constant level. Correlation of expression levels with enzyme activity: Hexokinase activity declined during fruit development, as did expression of $h k 1$ and $h k 2$ (as was described by Menu et al. 2001). Expression of $h k 4$ showed a temporal increase, peaked around DAP 37 and declined during ripening, correlating with starch biosynthesis in plastids.

Phosphoglucomutase activity declined during early fruit development, as did expression levels of the cytosolic isoform. In fruits of S. lycopersicum, the highest expression was found in ripe fruits, which was not the case for fruits of the wild accessions.

Expression of cytosolic phosphoglucoisomerase was constantly low in the developing fruits of all three tomato accessions. As ripening approached for fruits from S. lycopersicum, pgi expression levels increased, while expression in fruits of the wild accessions did not change significantly. Activity of the enzyme declined during early fruit development and so it seems unlikely that the activity of this enzyme is regulated by the gene expression level alone.

\section{Conclusion}

The fruit-bearing tomato accessions used in this study show that although processes involved in fruit growth and development are highly conserved, differences in the regulation of enzymes involved in carbohydrate metabolism at the level of gene expression, in enzyme activity and in the spatial localization of enzyme activity result in different carbohydrate compositions for fruits of different tomato accessions. In the future we would like to study the effect of the genes from the wild accessions in the background of domesticated tomato on carbohydrate metabolism during fruit growth and development. This could provide information how the differences in regulation of carbohydrate metabolism that we observe between the accessions contribute to the different phenotypes.

Acknowledgments This research was supported by Stichting Technologie Wetenschappen grant WPB.5769. N. Appeldoorn, who designed the experiments and was involved in most of the work described in this paper, died suddenly in February of 2006. He is missed by his friends and colleagues in the department of Plant Breeding. B. Kloosterman's help in analyzing the gene expression data is appreciated.

\section{References}

Appeldoorn NJG, de Bruijn SM, Koot-Gronsveld EAM, Visser RGF, Vreugdenhil D, van der Plas LHW (1997) Developmental changes of enzymes involved in the conversion of sucrose to hexose-phosphate during early tuberisation of potato. Planta 202:220-226 
Appeldoorn NJG, de Bruin SM, Koot-Gronsveld EAM, Visser RGF, Vreugdenhil D, van der Plas LHW (1999) Developmental changes in enzymes involved in the conversion of hexose-phosphate and its subsequent metabolites during early tuberisation of potato. Plant Cell Environ 22:1085-1096

Balibrea ME, Cuarttero J, Bolarin MC, Perez-Alfocea F (2003) Sucrolytic activities during fruit development of Lycopersicum genotypes differing in tolerance to salinity. Physiol Plant 118:38-46

Bunger-Kibler S, Bangerth F (1983) Relationship between cell number, cell size and fruit size of seeded fruits of tomato (Lycopersicum esculentum Mill) and those induced parthenocarpically by the application of plant growth regulators. Plant Growth Regul $1: 143-154$

Chengappa S, Loader N, Shields N (1998) Cloning expression and mapping of a second tomato (Lycopersicum esculentum) sucrose synthase gene, Sus 3 (accession nos. AJ011319, AJ011534) (PGR98-190). Plant Physiol 118:1533

Cong B, Liu J, Tanksley D (2002) Natural alleles at a tomato fruit size quantitative trait locus differ by heterochronic regulatory mutations. Proc Natl Acad Sci USA 99:13606-13611

Cosgrove DJ (1997) Relaxation in a high stress environment: the molecular basis of extendible cell walls and cell enlargement. Plant Cell 9:1031-1041

Dinar M, Stevens MA (1981) The relationship between starch accumulation and soluble solids content of tomato fruits. J Am Soc Hortic Sci 106:415-418

Eshed Y, Zamir D (1995) An introgression line population of Lycopersicum pennellii in the cultivated tomato enables the identification and fine mapping of yield associated QTLs. Genetics 141:11471162

Francis D, Halford NG (2006) Nutrient sensing in plants. Plant Mol Biol 60:981-993

Frary A, Nesbitt TC, Frary A, Grandillo S, Knaap van der E, Cong B, Liu J, Meller J, Elber R, Alpert KB, Tanksley SD (2000) A quantitative trait locus key to the evolution of tomato fruit size. Science 289:85-88

Fridman E, Carrari F, Liu YS, Fernie AR, Zamir D (2004) Zooming in on a quantitave trait for tomato yield using interspecific introgressions. Science 305:1786-1789

German MA, Dai N, Chmelntsky I, Sobolev I, Salts Y, Barg R, Schaffer AA, Granot D (2002) LeFRK4, a novel tomato (Lycopersicum esculentum Mill) fructokinase specifically expressed in stamens. Plant Sci 163:607-613

Gillaspy G, Ben-David H, Gruissem W (1993) Fruits: a developmental perspective. Plant Cell 5:1439-1451

Godt DE, Roitsch T (1997) Regulation and tissue-specific distribution of mRNA's for three extracellular invertase isozymes of tomato suggest an important function in establishing and maintaining sink metabolism. Plant Physiol 115:273-282

Ho LC, Hewitt JD (1986) Fruit development. In: Atherton JG, Rudich J (eds) The tomato crop. Chapman \& Hall, London, pp 201-240

Joubes J, Phan T-H, Just D, Rothan C, Bergounioux C, Raymond P, Chevalier C (1999) Molecular and biochemical characterization of the involvement of cyclin-dependent kinase A during the early development of tomato fruit. Plant Physiol 121:857-869

Klann EM, Chetelat RT, Bennet AB (1993) Expression of acid invertase gene controls sugar composition in tomato (Lycopersicum) fruit. Plant Physiol 103:863-870

Knapp S, Bohsh L, Nee M, Spooner DM (2004) Solanaceae-a model for linking genomics with biodiversity. Comp Funct Genomics $5: 285-291$
Koch K (2004) Sucrose metabolism: regulatory mechanisms and pivotal roles in sugar sensing and plant development. Curr Opin Plant Biol 7:235-246

Menu T, Rothan C, Dai N, Petreikov M, Etienne C, Destrac-Irvine A, Schaffer A, Granot D, Ricard B (2001) Cloning and characterization of a cDNA encoding hexokinase from tomato. Plant Sci 160:209-218

Miron D, Schaffer AA (1991) Sucrose phosphate synthase, sucrose synthase, and invertase activities in the developing fruits of $\mathrm{Lyco}$ persicum esculentum Mill. and the sucrose accumulating Lycopersicum hirsutum Humb. and Bonpl. Plant Physiol 95:623-627

Miron D, Petreikov M, Carmi N, Shen S, Levin I, Granot D, Zamski E, Schaffer AA (2002) Sucrose uptake, invertase localization and gene expression in developing fruit of Lycopersicum esculentum and the sucrose-accumulating Lycopersicum hirsutum. Physiol Plant 115:35-47

Obiadalla-Ali H, Fernie AR, Kossmann J, Lloyd JR (2004) Developmental analysis of carbohydrate metabolism in tomato ( Lycopersicum esculentum cv. Micro-Tom) fruits. Physiol Plant 120:196-204

Pien S, Wyrzykowska J, Fleming AJ (2001) Novel marker genes for early leaf development indicates spatial regulation of carbohydrate metabolism within the apical meristem. Plant J 25:663-674

Roitsch T, Gonzalez MC (2004) Function and regulation of plant invertases: sweet sensations. Trends Plant Sci 9:606-613

Schaffer AA, Petreikov M (1997) Sucrose-to-starch metabolism in tomato fruit undergoing transient starch accumulation. Plant Physiol 113:739-746

Schaffer AA, Levin I, Oguz I, Petreikov M, Cincarevsky F, Yeselson Y, Shen S, Gilboa N, Bar M (2000) ADPglucose pyrophosphorylase activity and starch accumulation in immature tomato fruit: the effect of a Lycopersicum hirsutum-derived introgression encoding for the large subunit. Plant Sci 152:135-144

Schauer N, Zamir D, Fernie AR (2005) Metabolic profiling of leaves and fruit of wild species tomato: a survey of the Solanum lycopersicum complex. J Exp Bot 56:297-307

Sergeeva LI, Vreugdenhil D (2000) In-situ staining of activities involved in carbohydrate metabolism in plant tissues. J Exp Bot $53: 361-370$

Stommel JR (1992) Enzymic components of sucrose accumulation in the wild tomato species Lycopersicum peruvianum. Plant Physiol 99:324-328

Sun J, Loboda T, Sung S-J, Black CC (1992) Sucrose synthase in wild tomato, Lycopersicon chmielewskii, and tomato fruit sink strength. Plant Physiol 98:1163-1169

Wang F, Sanz A, Brenner ML, Smith A (1993) Sucrose synthase, starch accumulation, and tomato fruit sink strength. Plant Physiol 101:321-327

Wang F, Smith AG, Brenner ML (1994) Temporal and spatial expression pattern of sucrose synthase during tomato fruit development. Plant Physiol 104:535-540

Weber H, Heim U, Golombek S, Borisjuk L, Manteuffel R, Wobus U (1998) Expression of a yeast-derived invertase in developing cotyledons of Vicia narbonensis alters the carbohydrate state and affects storage functions. Plant J 16:163-172

Yelle S, Hewitt JD, Robinson N, Damon S, Benett AB (1988) Sink metabolism in tomato fruit III analysis of carbohydrate assimilation in a wild species. Plant Physiol 87:737-740 